\title{
The analysis of pharmacokinetic and pharmacogenomic impact on gefitinib efficacy in advanced non-small cell lung cancer patients: results from a prospective cohort study
}

\author{
Yuxiang Ma", Shuang Xin ${ }^{2,3 \#}$, Qingguang Lin $^{1}$, Wei Zhuang ${ }^{2}$, Yuanyuan Zhao ${ }^{1}, X_{i a} Z_{h u^{2}}$, Hongyun Zhao ${ }^{1}$, \\ Min Huang ${ }^{2}$, Xu Xun ${ }^{3}$, Yunpeng Yang ${ }^{1}$, Wenfeng Fang ${ }^{1}$, Li Zhang ${ }^{1}$, Xueding Wang ${ }^{2}$ \\ ${ }^{1}$ Department of Medical Oncology, Sun Yat-sen University Cancer Center, State Key Laboratory of Oncology in South China; Collaborative \\ Innovation Center for Cancer Medicine, Guangzhou 510060, China; ${ }^{2}$ Institute of Clinical Pharmacology, School of Pharmaceutical Sciences, Sun \\ Yat-sen University, Guangzhou 510060, China; ${ }^{3}$ BGI-Shenzhen, Shenzhen 518083, China \\ Contributions: (I) Conception and design: Y Ma, S Xin, L Zhang, X Wang; (II) Administrative support: L Zhang, X Wang; (III) Provision of study \\ materials or patients: Y Ma, Q Lin, Y Zhao, H Zhao, Y Yang, W Fang, L Zhang; (IV) Collection and assembly of data: S Xin, W Zhuang, X Zhu, \\ M Huang, X Xun, X Wang; (V) Data analysis and interpretation: Y Ma, S Xin; (VI) Manuscript writing: All authors; (VII) Final approval of \\ manuscript: All authors. \\ \#These authors contributed equally to this work. \\ Correspondence to: Li Zhang, Professor. Department of Medical Oncology, State Key Laboratory of Oncology in South China, Collaborative \\ Innovation Center for Cancer Medicine, Sun Yat-sen University Cancer Center, 651\# Dongfeng Road, East, Guangzhou 510060, China. \\ Email: zhangli63@hotmail.com; Xueding Wang, Professor. Institute of Clinical Pharmacology, School of Pharmaceutical Sciences, Sun Yat-sen \\ University, 74\# Zhongshan Road, Section 2, Guangzhou 510080, China. Email: wangxd@mail.sysu.edu.cn.
}

Background: The current study is aimed to examine the impact of pharmacokinetics and gene polymorphisms of enzymes involving in absorption, distribution, metabolism and excretion (ADME) on the efficacy of gefitinib in non-small cell lung cancer (NSCLC) patients.

Methods: Eligible patients with indication of gefitinib treatment were prospectively enrolled in this study. Two peripheral blood samples at baseline and before cycle 2 day 1 were collected for the detection of single nucleotide polymorphisms (SNPs) of drug $\mathrm{ADME}$ enzymes and trough drug concentration $\left(\mathrm{C}_{\text {trough }}\right)$ at steady state. Thirteen SNPs were genotyped using the Sequenom Massarray system. $\mathrm{C}_{\text {trough }}$ was determined by validated high-performance liquid chromatographic method with tandem mass spectrometric (LC-MS/MS).

Results: Fifty-eight NSCLC patients were enrolled in this study. The median of $\mathrm{C}_{\text {trough }}$ was $175 \mathrm{ng} /$ $\mathrm{mL}$ (range from 47.8 to $470 \mathrm{ng} / \mathrm{mL}$ ). The trough concentration was not associated with either objective response or progression free survival (PFS). $\mathrm{C}_{\text {trough }}$ was significantly lower in CYP3A4 rs2242480 CC + CT genotype than in TT genotype $(\mathrm{P}=0.019)$ and in ABCG2 rs2231142 AA genotype than in AC + CC genotype (P=0.031). ABCB1 rs2032582 dominant model was significantly correlated with overall response rate (ORR) and patients with GG phenotype respond better than patients with GT + TT phenotypes (84.6\% vs. 51.2\%, $\mathrm{P}=0.032)$. ABCB1 rs10256836 recessive model was significantly correlated with PFS and patients with GG phenotype achieved longer PFS than patients with $\mathrm{GC}+\mathrm{CC}$ phenotypes (17.40 vs. 10.33 months, $\mathrm{P}=0.040)$. Conclusions: The $\mathrm{C}_{\text {trough }}$ of gefitinib was significantly different between CYP $3 A 4$ and ABCG2 genotypes, but not with the efficacy of gefitinib treatment. $A B C B 1$ rs2032582 and rs10256836 polymorphisms were correlated treatment outcome. Polymorphisms analysis of $A B C B 1$ could be a predictive biomarker for gefitinib treatment.

Keywords: Non-small cell lung cancer (NSCLC); gefitinib; pharmacokinetic; $A B C B 1$; single nucleotide polymorphisms (SNPs)

Submitted Oct 05, 2019. Accepted for publication Nov 29, 2019.

doi: $10.21037 / \mathrm{atm} .2019 .12 .60$

View this article at: http://dx.doi.org/10.21037/atm.2019.12.60 


\section{Introduction}

Non-small cell lung cancer (NSCLC) patients containing sensitive somatic mutations of the epidermal growth factor receptor $(E G F R)$ gene, such as the small deletions [747-750] and point mutations at codon 858 (L858R), are highly responsive to gefitinib $(1,2)$. However, there are still $30 \%$ patients with EGFR mutations could not benefit from gefitinib treatment. Thus, it's important to identify biomarkers that allow clear separation of patients with or without a relevant chance of clinical benefit from this drug $(2,3)$. Recently findings suggest that concomitant oncogenes strongly correlated with treatment outcome of gefitinib, and indicate poor clinical benefit, such as TP53, KRAS, MYC, $A P C$, etc. $(4,5)$. Some studies focus on the genes involved in drug targets or signaling pathways $(6,7)$. The deletion polymorphism of $B I M$, a pro-apoptotic member of the $B C L 2$ family, could lead to intrinsic resistance to gefitinib $(8,9)$.

However, very few studies focus on the pharmacogenomics impact of gefitinib on its treatment outcome. A different approach is to identify germline gene polymorphisms of enzymes involving in gefitinib absorption, distribution, metabolism and excretion (ADME) processes. The ADME of a drug is largely a host-mediated process. As a tyrosine kinase inhibitor, the efficacy of gefitinib in vivo could be significantly affected by genetic variability of these potential pharmacokinetics or pharmacogenomics linked enzymes $(10,11)$. ATP-binding cassette $(A B C)$ transporters function as substrate enzymes for multiple compounds and play a leading role in transporting drugs through the membrane between or out of body compartments (12-14). Cytochrome $\mathrm{P} 450$ proteins including CYP3A5, CYP2D6, $C Y P 3 A 4, C Y P 1 A 1, C Y P 1 A 2$ and $P O R$ are the main metabolizing enzymes involved in gefitinib metabolism (15-17). A variety of single-nucleotide polymorphisms (SNPs) in these enzymes have been described to predict toxicities and efficacy of chemotherapeutic agents $(18,19)$.

However, few studies have determined the impact of gene polymorphisms of enzymes in ADME processes on the efficacy of gefitinib in advanced NSCLC patients with EGFR mutations. Therefore, this study is aimed to investigate whether gene polymorphisms of enzymes in ADME processes could be used as predictive biomarkers for gefitinib.

\section{Methods}

\section{Patients and study design}

Patients were enrolled in this study prospectively. Key eligible criteria included histologically confirmed NSCLC, indication of gefitinib treatment (e.g., $E G F R$ active mutation, unknown EGFR status failed standard treatment), evaluable disease according to the Response Evaluation Criteria in Solid Tumor (RECIST) v1.1, $\geq 18$ years old and Eastern Cooperative Oncology Group (ECOG) performance score $(\mathrm{PS}) \leq 2$. Gefitinib was administrated 250 $\mathrm{mg}$ daily between 8 am to 9 am and consecutive treatment for one month was counted for one cycle. Anti-tumor activities were evaluated by investigators per RECIST v1.1 using image examination (computed tomography or magnetic resonance imaging scan) at baseline, first cycle (1 month), and every 2 cycles after. Overall response rate (ORR) included complete response (CR) and partial response (PR). Disease control rate (DCR) included CR, PR and stable disease (SD). Progression free survival (PFS) was defined as the time from the first dose to progression disease (PD), death and the start of second systemic treatment at the nearest evaluation before cutoff or the earliest event that shall prevail. This study was in accordance with the International Standards of Good Clinical Practice and approved by Sun Yat-sen University Cancer Center Independent Review Board (B2013-038-01) and registered on clinicaltrial.gov (NCT01994057). Written informed consents were provided by all patients.

\section{Samples collection and detection}

Two peripheral blood samples $(2 \mathrm{~mL})$ were collected for all patients using EDTA vacuum tubes. The first one was drawn before first gefitinib dose and the second one was drawn within $5 \mathrm{~min}$ before gefitinib administration at day 1 of cycle 2 . Samples were stored at $2-8{ }^{\circ} \mathrm{C}$ and centrifuged within $4 \mathrm{~h}$ to separate plasma for somatic mutation detection. White blood cells were used for germline mutation detection. Both plasma and white blood cells were stored at $-80{ }^{\circ} \mathrm{C}$ until analysis. The plasma of second blood was collected to measure the trough concentration of gefitinib at steady state using validated high-performance liquid chromatography with tandem mass spectrometry (LC-MS/MS) (20). EGFR mutations in primary tumors, 
metastatic lymph nodes or pleural effusion were detected using direct sequencing or real-time PCR (RT-PCR).

\section{Genotype analysis}

DNAs were extracted using the Genome TIANGEN Blood DNA Extraction Kit (AP348, China, Beijing). The quantity and quality of the extracted DNA were measured by calculating their optical density using ultraviolet spectrophotometer. SNPs were genotyped by matrixassisted laser desorption/ionization time-of-flight platform using the Sequenom Massarray system (San Diego, CA, USA). Thirteen SNPs with allele frequency $>5 \%$ in Chinese population were used for genotyping including CYP1A1 (rs2606345, rs1048943), CYP1A2 (rs762551), CYP3A4 (rs2242480), cytochrome $\mathrm{P} 450$ reductase (POR) (rs1057868, rs17685), UGT1A7 (rs6759892), ABCB1 (rs10256836, rs1045642, rs1128503, rs2032582) and $A B C G 2$ (rs2231137, rs2231142). Since multiple genetic models have been adapted to explore the biological rationales behind the preference of these genetic models and there is no concrete evidence for each SNP, in this research, the allele with higher frequency was considered as the dominant allele and its homozygote and heterozygote genotypes were categorized as the dominant genotypes. Meanwhile, the homozygote genotype of the allele with lower frequency was considered as recessive genotype $(21,22)$.

\section{Statistical analysis}

Clinical and experimental data were imported using EpiData 3.0. Statistical analyses were performed using SPSS v13 statistical software (USA). All descriptive data were expressed as mean \pm standard deviation and categorical variables were presented as counts and percent. The distribution of genotypes was tested for Hardy-Weinberg equilibrium (HWE). Fisher's exact test and log-rank test were used to compare ORR and PFS in different genotypes and clinical characteristics. Univariate analysis was applied in SNPs and ORR correlation study as unadjusted results. With consideration of clinical confounding factors, multivariate logistic regression was used to analyze the correlation as adjusted results. Multivariate logistic regression was used to reanalyze the statistical significance of each marked SNP with ORR. Odds ratios (OR) and $95 \%$ confidence interval (95\% CI) were estimated in all univariate analysis and multivariate analysis. The Wilcoxon Mann-Whitney U test and Kruskal-Wallis H test was adopted to test the difference in gefitinib trough concentration between different genotype groups. A twotailed $\mathrm{P}$ value of 0.05 indicated statistical significance. The figures were drawn using the GraphPad Prism5.0.

\section{Results}

\section{Patients}

A total of 58 NSCLC patients from Sun Yat-sen University Cancer Center from July 2011 to January 2014 were consecutively enrolled into this study. Data cutoff was set on April 30, 2015. Patients' demographic and clinical characteristics are shown in Table 1. The population was made up of $48 \%$ male and $52 \%$ female, with a median age of 56 years at diagnosis. Most of them (90\%) had adenocarcinoma. Twenty-two (38\%) patients harbored EGFR exon 19 deletion and 27 (47\%) harbored EGFR exon $21 \mathrm{~L} 858 \mathrm{R}$ point mutation. Thirty-five (60\%) patients achieved PR with ORR of $60 \%$ and DCR of $95 \%$. The datasets with detailed disease description were listed in (http://cdn.amegroups.cn/static/application/05c49f1f896 37a6bb3769bc81ba85e62/atm.2019.12.60-1.xlsx) with the private information blinded. The correlation of baseline clinical characteristics with ORR and PFS were analyzed and no significant clinical confounding characters had significant effect on gefitinib efficacy (Figure 1).

\section{Genotypes and pharmacokinetics}

The distributions of genotypes of all 13 SNPs were consistent with Hardy-Weinberg equilibrium (Table S1). Population distribution analysis indicated that the frequencies of SNPs in Chinese were highly consistent with those in Japanese NSCLC patients, but significantly different those in Caucasians and African Americans (Table S2).

Pharmacokinetic results are showed in Figure S1. The $\mathrm{C}_{\text {trough }}$ of gefitinib was in the range of $47.8-470 \mathrm{ng} / \mathrm{mL}$ with median value of $175 \mathrm{ng} / \mathrm{mL}$ and interquartile range of $130.5-236.6 \mathrm{ng} / \mathrm{mL}$. Nonparametric tests were adopted to test the difference of $\mathrm{C}_{\text {trough }}$ of gefitinib among different genotype groups (Table S3). In CYP3A4 rs2242480 dominant model, the $\mathrm{C}_{\text {trough }}$ of gefitinib was significantly lower in patients with CC + CT genotypes than patients with TT genotype (Wilcoxon Mann-Whitney U test, $\mathrm{P}=0.019$, Figure S2). For $A B C G 2$ rs2231142, the $\mathrm{C}_{\text {trough }}$ of gefitinib was significantly different among patients with different genotypes (Kruskal-Wallis $\mathrm{H}$ test, $\mathrm{P}=0.045$ ). The 
Table 1 Patients' demographics and baseline clinical characteristics

\begin{tabular}{|c|c|}
\hline Characters & No. of patients [\%] \\
\hline \multicolumn{2}{|l|}{ Gender } \\
\hline Male & $28[48]$ \\
\hline Female & $30[52]$ \\
\hline Age, median (range), years & $56[31-77]$ \\
\hline BSA, median (range), $\mathrm{m}^{2}$ & $1.64(1.26-2.06)$ \\
\hline \multicolumn{2}{|l|}{ ECOG PS } \\
\hline $0-1$ & 45 [78] \\
\hline$>2$ & $10[17]$ \\
\hline Unknown & $3[5]$ \\
\hline \multicolumn{2}{|l|}{ Smoking history } \\
\hline Smoker & $36[62]$ \\
\hline Non-smoker & 18 [31] \\
\hline Unknown & $4[7]$ \\
\hline \multicolumn{2}{|l|}{ Disease staging } \\
\hline Recurrent & $21[36]$ \\
\hline IIIB or IV & 37 [64] \\
\hline \multicolumn{2}{|l|}{ Pathology } \\
\hline Adenocarcinoma & $52[90]$ \\
\hline Adenosquamous carcinoma & $2[4]$ \\
\hline Squamous carcinoma & $4[7]$ \\
\hline \multicolumn{2}{|l|}{ EGFR mutation status } \\
\hline Exon19 deletions & 22 [38] \\
\hline Exon21 L858R & $27[47]$ \\
\hline Other sensitive mutations ${ }^{*}$ & $6[10]$ \\
\hline Unknown & $3[5]$ \\
\hline \multicolumn{2}{|l|}{ Treatment line of gefitinib } \\
\hline $1^{\text {st }}$ & $23[40]$ \\
\hline $2^{\text {nd }}$ or later & $35[60]$ \\
\hline \multicolumn{2}{|l|}{ Platinum based chemotherapy } \\
\hline With & $18[31]$ \\
\hline Without & 40 [69] \\
\hline \multicolumn{2}{|l|}{ Best response to gefitinib } \\
\hline Partial response & $35[60]$ \\
\hline Stable disease & $20[34]$ \\
\hline Progressive disease & $3[5]$ \\
\hline \multicolumn{2}{|l|}{ Progression free survival } \\
\hline$\leq 10$ months & $24[41]$ \\
\hline$>10$ months & 34 [59] \\
\hline
\end{tabular}

*, 3 patients with exon 21L861Q, 2 with exon 20S768I and 1 with exon 18G719X. Staging: according to IASLC 2007 staging method; BSA, body surface area; ECOG PS, Eastern Cooperative Oncology Group-performance status.
$\mathrm{C}_{\text {trough }}$ of gefitinib was significantly lower in patients with AA genotype than in patients with $\mathrm{AC}+\mathrm{CC}$ genotype (Wilcoxon Mann-Whitney U test, $\mathrm{P}=0.031$, Figure S3).

\section{Association between gefitinib pharmacokinetics and efficacy}

Nonparametric tests were adopted to test the difference in $\mathrm{C}_{\text {trough }}$ of gefitinib between patients with different gefitinib responses. The median $\mathrm{C}_{\text {trough }}$ of gefitinib was $173.9 \mathrm{ng} / \mathrm{mL}$ with interquartile range of $108-231 \mathrm{ng} / \mathrm{mL}$ in PR group and $191.5 \mathrm{ng} / \mathrm{mL}$ with interquartile range of $135.5-275.5 \mathrm{ng} / \mathrm{mL}$ in $\mathrm{SD}+\mathrm{PD}$ group, respectively $(\mathrm{P}=0.236)$. $\mathrm{X}$-Tile was used to determine the cutoff value of $\mathrm{C}_{\text {trough }}$ based on ORR $\left(\mathrm{C}_{\text {trough }}\right.$ cutoff at $200 \mathrm{ng} / \mathrm{mL}$ ) (23). Chi-square test showed that the ORR was not significantly different in patients with $\mathrm{C}_{\text {trough }}$ $>200 \mathrm{ng} / \mathrm{mL}$ and patients with $\mathrm{C}_{\text {trough }}<200 \mathrm{ng} / \mathrm{mL}$ [64\% (23/36) vs. $55 \%$ (12/22), $\mathrm{P}=0.480]$.

In addition, no significant correlation was found between patients' PFS and $\mathrm{C}_{\text {trough }}$ of gefitinib either. The median PFS of patients with $\mathrm{C}_{\text {trough }}>200$ and $<200 \mathrm{ng} / \mathrm{mL}$ was 11.80 and 14.00 months, respectively ( $\mathrm{P}=0.78$, Table S4, Figure S4).

\section{Association between genotypes and efficacy}

We analyzed the impact of gene polymorphisms on the efficacy of gefitinib treatment in all 58 patients. With consideration of clinical confounding factors, multivariate logistic regression was used to re-analyze each SNP and those factors with ORR as an adjusted result. The results indicated that 3 SNPs (CYP1A2 rs762551 recessive model, POR rs1057868 dominant model and ABCB1 rs2032582 dominant model) were significant high-risk determinants for ORR as shown in Table 2. Further multivariate logistic regression (stepwise method) was applied with considering 2 SNPs and clinical confounders as independent covariate factors. The results suggested only $A B C B 1$ rs2032582 dominant model was a significant high-risk determinant for ORR (GT + TT/GG: HR $=0.111,95 \%$ CI: 0.013 to 0.965 ). The response rate was significantly lower in patients with ABCB1 rs2032582 (GT + TT) genotypes than in patients with ABCB1 rs2032582 (GG) genotype, with ORR of $51.2 \%$ and $84.6 \%$, respectively $(\mathrm{P}=0.032$, Tables $3, S 5)$.

All 58 patients were analyzed to identify the determinant of PFS in the 13 SNPs. Kaplan-Meier curves and logrank test were applied to compare the PFS of patients with different gene polymorphisms in gefitinib treatment. The results indicated that $A B C B 1$ rs10256836 recessive model was significantly associated with PFS of patients subjected 


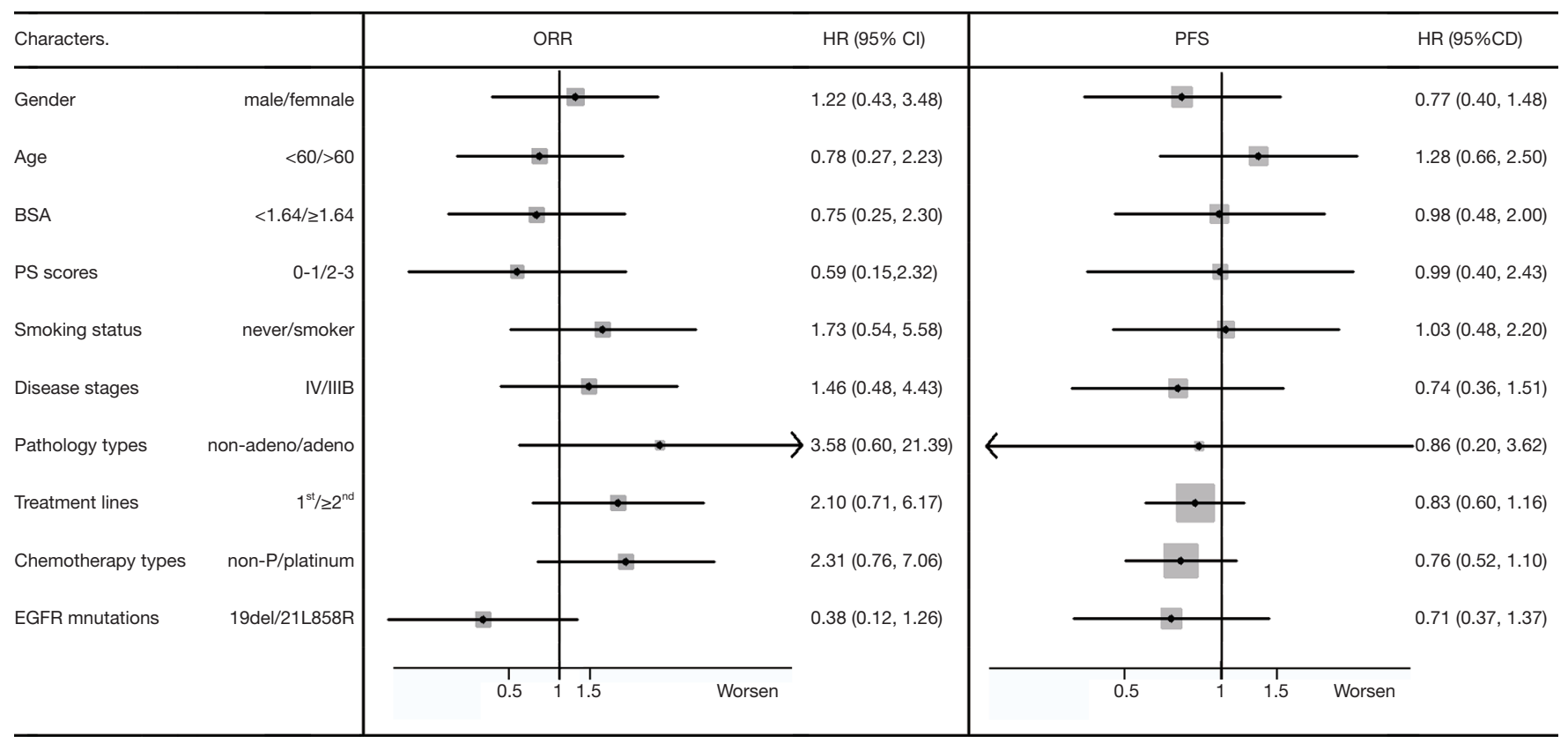

Figure 1 The impact of patients' demographics and clinical characteristics on Gefitinib efficacy (overall response rate and progression free survival). ORR, overall response rate; $95 \% \mathrm{CI}, 95 \%$ confidence interval.

to gefitinib treatment, as shown in Table 4 and Figure 2. CYP3A4 rs2242480 dominant model was excluded due to unbalanced proportion of CC + CT (54/57) and TT genotype (3/57). For ABCB1 rs10256836 recessive model, the median PFS was 10.33 months (95\% CI: 7.58-13.09) for patients with GC + CC genotypes, significantly shorter than that of 17.40 months (95\% CI: 12.19-22.61) for patients with $\mathrm{GG}$ genotype $(\mathrm{P}=0.04)$. The Cox regression with stepwise methods was adopted to select the significant determinant of PFS in gefitinib treatment (Table S6). The results showed that $A B C B 1$ rs10256836 recessive models were significantly associated with PFS of patients subjected to gefitinib treatment.

\section{Discussion}

Current study explored the impacts of blood $\mathrm{C}_{\text {trough }}$ of gefitinib and ADME enzymes on the outcomes of gefitinib treatment. The results from 58 patients indicated that the $\mathrm{C}_{\text {trough }}$ of gefitinib was associated with neither patient' response to gefitinib nor immediate survival, while ATPbinding cassette gene polymorphisms were significantly related with the outcome of gefitinib treatment.

In this research, the $\mathrm{C}_{\text {trough }}$ of gefitinib was significantly different between patients with CYP3A4 rs2242480 and
$A B C G 2$ rs2231142, implying that the blood $\mathrm{C}_{\text {trough }}$ of gefitinib might be influenced by the polymorphisms of metabolic enzymes in the liver and transporters in the kidney. Second, both preclinical and clinical researches revealed that the concentration of gefitinib in tumor and skin was much higher than its plasma concentration in xenograft mice and patients (24-26). Using positron emission tomography, ${ }^{11} \mathrm{C}$ and ${ }^{14} \mathrm{C}$ gefitinib was accumulated in tumor tissues and normal tissues such as skin and intestine rather than evenly distributed in blood, both in rat and human $(25,27,28)$. Haura's study indicated that gefitinib level in tumor was approximately 40 -fold higher than its plasma level (29). These findings indicated that the blood $\mathrm{C}_{\text {trough }}$ of gefitinib is not a good substitute indicator for its concentration in tumor, insistent with the previous research (20). Third, the ratio of gefitinib concentration in tumor to that in plasma is ranged from 1.12-250 to 1 (median 40 to 1 ), which demonstrated tremendous inter-individual variability (30). A previous research also indicated that the trough concentration at $\mathrm{d} 8$ and $\mathrm{d} 15$ was not associated with response rates or survival times with gefitinib (11). The polymorphisms of transporters (ABCB1) and metabolic enzymes (CYP1A1) in lung might contribute to the variability of tumor concentration (31). Therefore, it is reasonable to speculate that SNPs of these enzymes could 
Table 2 Analysis of Association of SNPs gene models with ORR with/without consideration of potential confounders

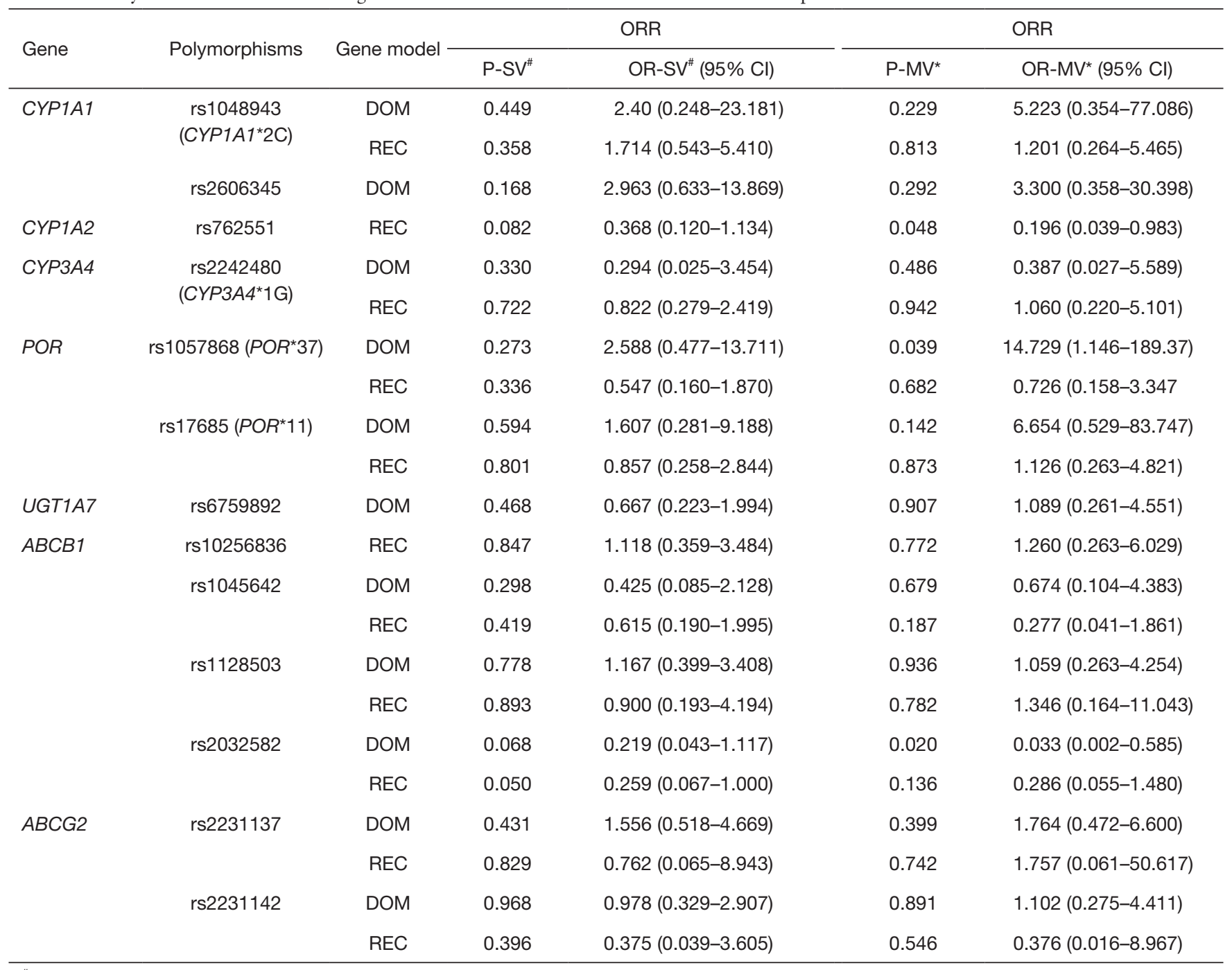

\#, single variant logistic analysis for the contribution of the SNPs gene models for the ORR; *, adjusted $\mathrm{P}$ value by multivariate logistic regression analysis (Enter method) for potential clinical confounders, including gender, BSA, age, PS, smoking history, staging, pathology, EGFR status, treatment lines and platinum chemotherapy. SV, single variant logistic analysis; MV, multivariate logistic regression analysis; ORR, overall response rate; OR, odds ratio; $95 \% \mathrm{Cl}, 95 \%$ confidence interval; DOM, dominant model; REC, recessive model; SNPs, single nucleotide polymorphisms.

Table 3 Response rate of gefitinib in $A B C B 1$ rs2032582 dominant model

\begin{tabular}{lccc}
\hline Objective response & rs2032582 (GG) & rs2032582 (TT + GT) & P value \\
\hline CR + PR & $11(84.6 \%)$ & $22(51.2 \%)$ & - \\
SD + PD & $2(15.4 \%)$ & $21(48.8 \%)$ & - \\
Total & 13 & 43 & 0.032 \\
\hline
\end{tabular}

$\mathrm{CR}$, complete response; PR, partial response; SD, stable disease; PD, progression disease. 
Table 4 Log-rank test for the association of SNPs gene models with PFS

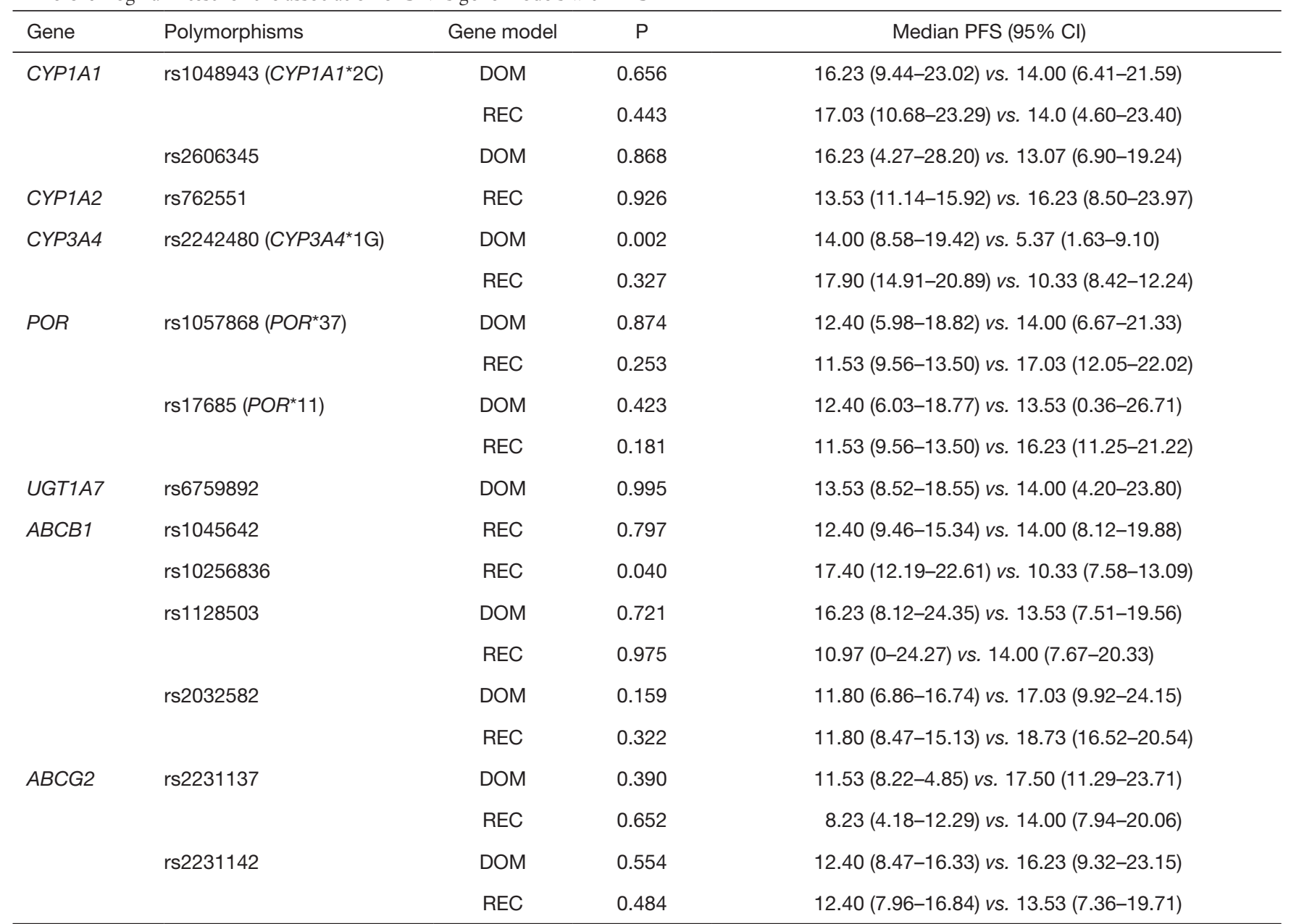

SNPs, single nucleotide polymorphisms; PFS, progression free survival; 95\% Cl, 95\% confident interval; DOM, dominant model; REC, recessive model.

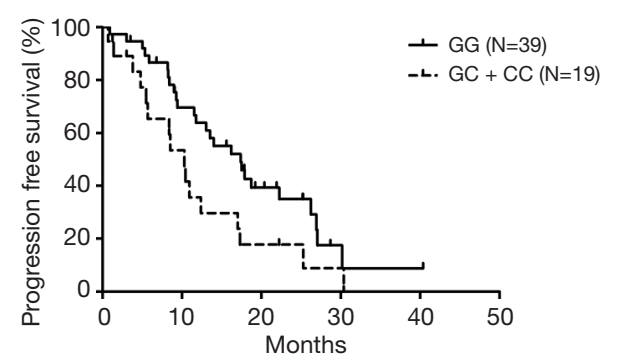

Figure 2 Kaplan-Meier curve and log-rank test for progressionfree survival in advanced NSCLC patients treated with gefitinib: association with $A B C B 1$ rs10256836 recessive model (GG vs. GC + CC). NSCLC, non-small cell lung cancer. cause variability of gefitinib concentration in tumor and affect tumor response.

$A B C$ transporters distributed as membrane proteins in various organs, where they functioned as substrate enzymes for multiple compounds, and played a leading role in transporting drugs through the membrane between or out of body compartments $(32,33)$. Thus, the genes polymorphisms of specific transporters that involved in these processes might have not negligible impact on the variation in drug response or toxicities. Vlaming's research indicated that human $A B C B 1$ and $A B C G 2$ transporters were over-expressed in NSCLC tumor cell lines (31). 
Based on that, our hypothesis is that SNPs affect the activities of $A B C B 1$ or $A B C G 2$ in tumor tissues, causing abnormal variability of gefitinib concentration in tumor and eventually leading to different response to gefitinib. Our findings in this research indicated that $A B C B 1 \mathrm{rs} 2032582$ and rs10256836 gene polymorphisms were highly correlated with gefitinib efficacy. Gefitinib is a substrate of $A B C B 1$ (32,33). ABCB1 rs2032582 G>T mutation G2677T/A is a nonsynonymous mutation in exon 21 . Three nucleotides (G/T/A) were in rs2032582, encoding 3 amino acids (Ala893Ser/Thr). However, the function of this SNP is controversial. Some studies concluded that rs $2032582 \mathrm{G}>\mathrm{T}$ mutation will weaken the drug efflux function of $A B C B 1$ $(34,35)$. Based on that, GG phenotype in rs2032582 is probably the risk factor of gefitinib response. Clinical data indicated that rs10256836 G>C mutation increased the expression or activity of transporters proteins (36-38). Our results also indicated patients with rs10256836 GG genotype had longer PFS, consistent with the previous research. Previous research also suggested that $A B C B 1$ rs1128503 TT genotype was a significant high-risk determinant of both skin rash and diarrhea (39). In this research, neither $A B C B 1$ rs1128503 nor rs1045642 was significantly associated with ORR and PFS. However, only polymorphisms have been detected in this cohort, the gene expression data and concentration data from target tissue would be helpful to give a better illustration to the complete pharmacokinetics and pharmacogenomics inter-individual variability. In vivo and in vitro experiments were needed to confirm our findings.

\section{Conclusions and limitation}

Our study indicated that gefitinib trough concentration was significantly different between CYP $3 A 4$ and $A B C G 2$ genotypes; blood gefitinib trough concentration was not associated with its efficacy. Moreover, pharmacogenomic analysis revealed that patients with GT + TT genotypes in $A B C B 1$ rs2032582 dominant model respond better to gefitinib and patients carried with GC + CC genotypes in $A B C B 1$ rs10256836 dominant recessive model had longer PFS after gefitinib treatment. However, our findings were based on a small sample prospective cohort study. Therefore, further randomized clinical trials must be conducted to confirm that correlation and to elucidate the biomarker function of $\mathrm{ABC}$ transporters family gene polymorphisms (ABCB1 rs2032582 and rs10256836) in clinical practice.

\section{Acknowledgments}

We thank the patients and their families for contributing to this study.

Funding: This study was supported by the National Nature Science Foundation of China (81973398 to X Wang, 81730103 to M Huang, 81872499 to L Zhang, 81473283 to X Wang), the National Key Research and Development Program of China (2016YFC0905000 to M Huang, 2016YFC0905503 to L Zhang), the Science, Technology and Innovation Commission of Shenzhen Municipality (JCYJ20170817145454378 to S Xin) and the 111 project (B16047 to M Huang).

\section{Footnote}

Conflicts of Interest: The authors have no conflicts of interest to declare.

Ethical Statement: The authors are accountable for all aspects of the work, and the questions related to the accuracy or integrity of any part of the work are appropriately investigated and resolved. The study was approved by the Ethical Committee of Sun Yat-sen University Cancer Center (B2013-08-01). Informed consent written informed consent was obtained from all participating subjects. This trial was registered at ClinicalTrials.gov. (NCT01994057, date of registration: 2013/11/23).

\section{References}

1. Mok TS, Wu YL, Thongprasert S, et al. Gefitinib or carboplatin - paclitaxel in pulmonary adenocarcinoma. $\mathrm{N}$ Engl J Med 2009;361:947-57.

2. Maemondo M, Inoue A, Kobayashi K, et al. Gefitinib or chemotherapy for non-small-cell lung cancer with mutated EGFR. N Engl J Med 2010;362:2380-8.

3. Mitsudomi T, Morita S, Yatabe Y, et al. Gefitinib versus cisplatin plus docetaxel in patients with non-small-cell lung cancer harbouring mutations of the epidermal growth factor receptor (WJTOG3405): an open label, randomised phase 3 trial. Lancet Oncol 2010;11:121-8.

4. Hong S, Gao F, Fu S, et al. Concomitant Genetic Alterations With Response to Treatment and Epidermal Growth Factor Receptor Tyrosine Kinase Inhibitors in Patients With EGFR-Mutant Advanced Non-Small Cell Lung Cancer. JAMA Oncol 2018;4:739-42.

5. Wang Z, Cheng Y, An T, et al. Detection of EGFR 
mutations in plasma circulating tumour DNA as a selection criterion for first-line gefitinib treatment in patients with advanced lung adenocarcinoma (BENEFIT): a phase 2, single-arm, multicentre clinical trial. Lancet Respir Med 2018;6:681-90.

6. Zhang X, Zhang Y, Tang H, et al. EGFR gene copy number as a predictive/biomarker for patients with nonsmall-cell lung cancer receiving tyrosine kinase inhibitor treatment: a systematic review and meta-analysis. J Investig Med 2017;65:72-81.

7. Dahabreh IJ, Linardou H, Kosmidis P, et al. EGFR gene copy number as a predictive biomarker for patients receiving tyrosine kinase inhibitor treatment: a systematic review and meta-analysis in non-small-cell lung cancer. Ann Oncol 2011;22:545-52.

8. Douillard JY, Shepherd FA, Hirsh V, et al. Molecular predictors of outcome with gefitinib and docetaxel in previously treated non-small-cell lung cancer: data from the randomized phase III INTEREST trial. J Clin Oncol 2010;28:744-52.

9. Zhao M, Zhang Y, Cai W, et al. The Bim deletion polymorphism clinical profile and its relation with tyrosine kinase inhibitor resistance in Chinese patients with nonsmall cell lung cancer. Cancer 2014;120:2299-307.

10. Kobayashi H, Sato K, Niioka T, et al. Relationship Among Gefitinib Exposure, Polymorphisms of Its Metabolizing Enzymes and Transporters, and Side Effects in Japanese Patients With Non-Small-Cell Lung Cancer. Clin Lung Cancer 2015;16:274-81.

11. Hirose T, Fujita K, Kusumoto S, et al. Association of pharmacokinetics and pharmacogenomics with safety and efficacy of gefitinib in patients with EGFR mutation positive advanced non-small cell lung cancer. Lung Cancer 2016;93:69-76.

12. Beretta GL, Cassinelli G, Pennati M, et al. Overcoming $\mathrm{ABC}$ transporter-mediated multidrug resistance: The dual role of tyrosine kinase inhibitors as multitargeting agents. Eur J Med Chem 2017;142:271-89.

13. Liu Y, Ramirez J, House L, et al. Comparison of the drugdrug interactions potential of erlotinib and gefitinib via inhibition of UDP-glucuronosyltransferases. Drug Metab Dispos 2010;38:32-9.

14. Agarwal S, Sane R, Gallardo JL, et al. Distribution of gefitinib to the brain is limited by $\mathrm{P}$-glycoprotein $(\mathrm{ABCB} 1)$ and breast cancer resistance protein (ABCG2)-mediated active efflux. J Pharmacol Exp Ther 2010;334:147-55.

15. Li J, Cusatis G, Brahmer J, et al. Association of variant
ABCG2 and the pharmacokinetics of epidermal growth factor receptor tyrosine kinase inhibitors in cancer patients. Cancer Biol Ther 2007;6:432-8.

16. McKillop D, McCormick AD, Millar A, et al. Cytochrome P450-dependent metabolism of Gefitinib. Xenobiotica 2005;35:39-50.

17. Li J, Zhao M, He P, et al. Differential metabolism of Gefitinib and erlotinib by human cytochrome P450 enzymes. Clin Cancer Res 2007;13:3731-7.

18. Goldstein DB, Tate SK, Sisodiya SM. Pharmacogenetics goes genomic. Nat Rev Genet 2003;4:937-47.

19. Ma Q, Lu AY. Pharmacogenetics, pharmacogenomics, and individualized medicine. Pharmacol Rev 2011;63:437-59.

20. Xin S, Zhao Y, Wang X, et al. The Dissociation of Gefitinib Trough Concentration and Clinical Outcome in NSCLC Patients with EGFR Sensitive Mutations. Sci Rep 2015;5:12675.

21. Clarke GM, Anderson CA, Pettersson FH, et al. Basic statistical analysis in genetic case-control studies. Nat Protoc2011;6:121-33.

22. Zhao F, Song M, Wang Y, et al. Genetic model. J Cell Mol Med 2016;20:765.

23. Camp RL, Dolled-Filhart M, Rimm DL. X-tile: a new bio-informatics tool for biomarker assessment and outcome-based cut-point optimization. Clin Cancer Res 2004;10:7252-9.

24. Marko-Varga G, Fehniger TE, Rezeli M, et al. Drug localization in different lung cancer phenotypes by MALDI mass spectrometry imaging. J Proteomics 2011;74:982-92.

25. McKillop D, Partridge EA, Kemp JV, et al. Tumor penetration of gefitinib (Iressa), an epidermal growth factor receptor tyrosine kinase inhibitor. Mol Cancer Ther 2005;4:641-9.

26. Marko-Varga G, Fehniger TE, Rezeli M, et al. Drug localization in different lung cancer phenotypes by MALDI mass spectrometry imaging. J Proteomics 2011;74:982-92.

27. Ballard P, Yates JW, Yang Z, et al. Preclinical Comparison of Osimertinib with Other EGFR-TKIs in EGFR-Mutant NSCLC Brain Metastases Models, and Early Evidence of Clinical Brain Metastases Activity. Clin Cancer Res 2016;22:5130-40.

28. Zhang MR, Kumata K, Hatori A, et al. (11C) Gefitinib ((11C) Iressa): radiosynthesis, in vitro uptake, and in vivo imaging of intact murine fibrosarcoma. Mol Imaging Biol 2010;12:181-91.

29. Haura EB, Sommers E, Song L, et al. A pilot study of 
preoperative gefitinib for early-stage lung cancer to assess intratumor drug concentration and pathways mediating primary resistance. J Thorac Oncol 2010;5:1806-14.

30. Cusatis G, Gregorc V, Li J, et al. Pharmacogenetics of ABCG2 and adverse reactions to gefitinib. J Natl Cancer Inst 2006;98:1739-42.

31. Vlaming ML, Läppchen T, Jansen HT, et al. PET-CT imaging with ((18)F)-gefitinib to measure Abcb1a/1b (Pgp) and Abcg2 (Bcrp1) mediated drug-drug interactions at the murine blood-brain barrier. Nucl Med Biol 2015;42:833-41.

32. Tamura M, Kondo M, Horio M, et al. Genetic polymorphisms of the adenosine triphosphate-binding cassette transporters (ABCG2, ABCB1) and gefitinib toxicity. Nagoya J Med Sci 2012;74:133-40.

33. Kimchi-Sarfaty C, Oh JM, Kim IW, et al. A "silent" polymorphism in the MDR1 gene changes substrate specificity. Science 2007;315:525-8.

34. Salama NN, Yang Z, Bui T, et al.MDR1 haplotypes significantly minimize intracellular uptake and transcellular P-gp substrate transport in recombinant LLC-PK1 cells. J
Pharm Sci 2006;95:2293-308.

35. Lin KM, Chiu YF, Tsai IJ, et al. ABCB1 gene polymorphisms are associated with the severity of major depressive disorder and its response to escitalopram treatment. Pharmacogenet Genomics 2011;21:163-70.

36. Daud AN, Bergman JE, Kerstjens-Frederikse WS, et al. The Risk of Congenital Heart Anomalies Following Prenatal Exposure to Serotonin Reuptake InhibitorsIs Pharmacogenetics the Key? Int J Mol Sci 2016. doi: 10.3390/ijms17081333.

37. Liu Y, Foulkes AS. Latent variable modeling paradigms for genotype-trait association studies. Biom J 2011;53:838-54.

38. Paule B, Castagne V, Picard V, et al. MDR1 polymorphism role in patients treated with cetuximab and irinotecan in irinotecan refractory colorectal cancer. Med Oncol 2010;27:1066-72.

39. Rudin CM, Liu W, Desai A, et al. Pharmacogenomic and pharmacokinetic determinants of erlotinib toxicity. J Clin Oncol 2008;26:1119-27.
Cite this article as: Ma Y, Xin S, Lin Q, Zhuang W, Zhao Y, Zhu X, Zhao H, Huang M, Xun X, Yang Y, Fang W, Zhang L, Wang X. The analysis of pharmacokinetic and pharmacogenomic impact on gefitinib efficacy in advanced non-small cell lung cancer patients: results from a prospective cohort study. Ann Transl Med 2019;7(24):806. doi: 10.21037/ atm.2019.12.60 


\section{Supplementary}

Table S1 Genotype frequency and Hardy-Weinberg equilibrium test for SNPs

\begin{tabular}{|c|c|c|c|c|c|c|c|}
\hline \multirow{2}{*}{ Gene } & \multirow{2}{*}{ Rs } & \multirow{2}{*}{$\mathrm{N}$} & \multicolumn{3}{|c|}{ Genotype frequency } & \multirow{2}{*}{ Minor allelic frequency } & \multirow{2}{*}{ HWE $P$ value } \\
\hline & & & wt/wt, n [\%] & $\mathrm{wt} / \mathrm{m}, \mathrm{n}[\%]$ & $\mathrm{m} / \mathrm{m}, \mathrm{n}[\%]$ & & \\
\hline \multirow{2}{*}{ CYP1A1 } & rs1048943 (CYP1A1*2C) & 53 & $29[54]$ & $19[37]$ & 5 [9] & 0.27 & 0.47 \\
\hline & rs2606345 & 58 & $50[86]$ & $7[12]$ & 1 [2] & 0.08 & 0.23 \\
\hline CYP1A2 & rs762551 (CYP1A2*1F) & 56 & $26[47]$ & $26[46]$ & $4[7]$ & 0.30 & 0.46 \\
\hline CYP3A4 & rs2242480 (CYP3A4*1G) & 57 & $25[45]$ & $29[50]$ & $3[5]$ & 0.30 & 0.14 \\
\hline \multirow[t]{2}{*}{$P O R$} & rs1057868 $\left(P O R^{\star} 37\right)$ & 55 & 18 [33] & $28[51]$ & $9[16]$ & 0.43 & 0.73 \\
\hline & rs17685 (POR*11) & 53 & 17 [33] & 29 [54] & $7[13]$ & 0.40 & 0.32 \\
\hline UGT1A7 & rs6759892 & 55 & 28 [52] & 25 [45] & 2 [3] & 0.26 & 0.20 \\
\hline \multirow[t]{4}{*}{$A B C B 1$} & rs1045642 & 54 & 19 [35] & 28 [53] & 7 [12] & 0.39 & 0.50 \\
\hline & rs10256836 & 58 & 39 [67] & 18 [31] & 1 [2] & 0.17 & 0.49 \\
\hline & rs1128503 & 58 & 24 [42] & $26[44]$ & $8[14]$ & 0.35 & 0.82 \\
\hline & rs2032582 & 56 & 12 [21] & $32[58]$ & 12 [21] & 0.50 & 0.28 \\
\hline \multirow[t]{2}{*}{ ABCG2 } & rs2231137 & 56 & $25[44]$ & 27 [49] & $4[7]$ & 0.32 & 0.36 \\
\hline & rs2231142 & 55 & $26[46]$ & 24 [45] & 5 [9] & 0.31 & 0.87 \\
\hline
\end{tabular}

HWE, Hardy-Weinberg equilibrium.

Table S2 Comparison of genotypes distributions in different populations

\begin{tabular}{llccccc}
\hline Gene & Rs & Minor allelic frequency & Han Chinese & Japanese & Caucasian & African American \\
\hline CYP1A1 & rs1048943 (CYP1A1*2C) & 0.27 & 0.26 & 0.25 & $0.03^{* *}$ & $0.01^{* *}$ \\
& rs2606345 & 0.08 & 0.03 & 0.03 & $0.45^{* *}$ & 0.17 \\
CYP1A2 & rs762551 (CYP1A2*1F) & 0.3 & 0.31 & 0.36 & 0.32 & 0.44 \\
CYP3A4 & rs2242480 (CYP3A4*1G) & 0.3 & 0.28 & 0.30 & 0.20 & $0.12^{* *}$ \\
POR & rs1057868 (POR*37) & 0.43 & 0.42 & 0.40 & 0.29 & $0.08^{* *}$ \\
& rs17685 (POR*11) & 0.4 & 0.28 & 0.36 & 0.29 & 0.29 \\
UGT1A7 & rs6759892 & 0.26 & 0.23 & 0.21 & $0.45^{* *}$ & $0.67^{* *}$ \\
ABCB1 & rs1045642 & 0.39 & 0.42 & 0.46 & 0.45 & $0.07^{* *}$ \\
& rs10256836 & 0.17 & 0.11 & 0.14 & $0.30^{* *}$ & 0.09 \\
& rs1128503 & 0.35 & 0.29 & 0.41 & 0.42 & $0.14^{* *}$ \\
& rs2032582 & 0.50 & 0.38 & 0.48 & 0.44 & $0.13^{* *}$ \\
ABCG2 & rs2231137 & 0.32 & 0.29 & 0.19 & $0.06^{* *}$ & $0.06^{* *}$ \\
& rs2231142 & 0.31 & 0.29 & 0.31 & $0.09^{* *}$ & $0.04^{* *}$ \\
\hline
\end{tabular}

${ }^{\star \star}$, the distribution of different alleles in different populations (Japanese/Caucasian/African American) compared with Han Chinese population by Chi-square test. 


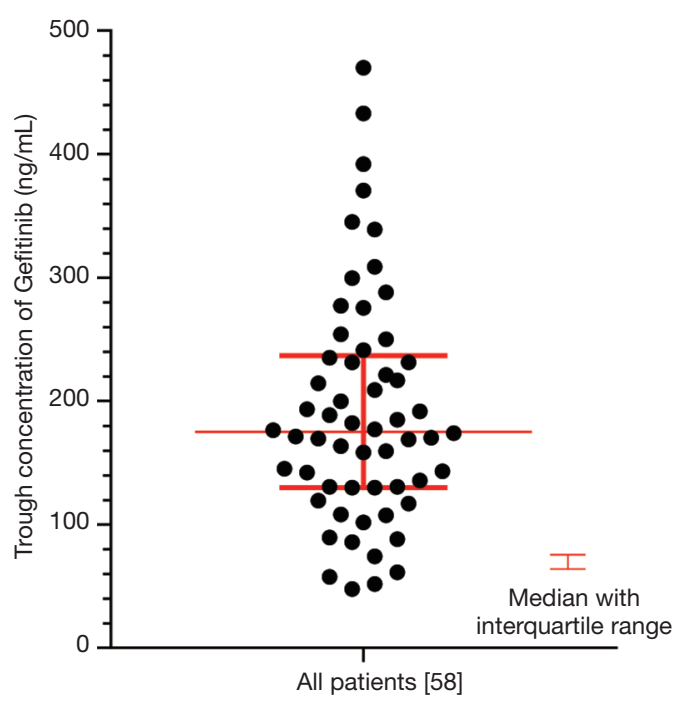

Figure S1 The distribution of gefitinib trough concentration in all 58 patients.
Table S3 The Wilcoxon Mann-Whitney U and Kruskal-Wallis H test for the gefitinib blood concentration among different genotype groups

\begin{tabular}{|c|c|c|c|c|}
\hline Gene & Polymorphisms & Gene model & $\mathrm{P}^{\#}$ & $P^{*}$ \\
\hline \multirow[t]{3}{*}{ CYP1A1 } & \multirow{2}{*}{$\begin{array}{l}\text { rs1048943 } \\
(C Y P 1 A 1 * 2 C)\end{array}$} & DOM & 0.203 & \multirow[t]{3}{*}{0.317} \\
\hline & & REC & 0.802 & \\
\hline & rs2606345 & DOM & 0.260 & \\
\hline CYP1A2 & rs762551 & REC & 0.954 & \\
\hline \multirow[t]{2}{*}{ СYP3A4 } & \multirow{2}{*}{$\begin{array}{l}\text { rs2242480 } \\
\left(C Y P 3 A 4^{*} 1 G\right)\end{array}$} & DOM & 0.019 & \multirow[t]{2}{*}{0.078} \\
\hline & & REC & 0.531 & \\
\hline \multirow[t]{4}{*}{ POR } & \multirow{2}{*}{$\begin{array}{l}\text { rs1057868 } \\
\left(P O R^{\star 37}\right)\end{array}$} & DOM & 0.302 & \multirow[t]{2}{*}{0.546} \\
\hline & & REC & 0.963 & \\
\hline & \multirow{2}{*}{$\begin{array}{l}\text { rs17685 } \\
\left(P O R^{\star 11}\right)\end{array}$} & DOM & 0.120 & \multirow[t]{2}{*}{0.242} \\
\hline & & REC & 0.879 & \\
\hline UGT1A7 & rs6759892 & DOM & 0.755 & \\
\hline \multirow[t]{7}{*}{$A B C B 1$} & \multirow[t]{2}{*}{ rs1045642 } & DOM & 0.479 & \multirow[t]{3}{*}{0.743} \\
\hline & & REC & 0.986 & \\
\hline & rs10256836 & REC & 0.565 & \\
\hline & \multirow[t]{2}{*}{ rs1128503 } & DOM & 0.130 & \multirow[t]{2}{*}{0.316} \\
\hline & & REC & 0.572 & \\
\hline & \multirow[t]{2}{*}{ rs2032582 } & DOM & 1.000 & \multirow[t]{2}{*}{0.168} \\
\hline & & REC & 0.069 & \\
\hline \multirow[t]{4}{*}{ ABCG2 } & \multirow[t]{2}{*}{ rs2231137 } & DOM & 0.585 & \multirow[t]{2}{*}{0.239} \\
\hline & & REC & 0.154 & \\
\hline & \multirow[t]{2}{*}{ rs2231142 } & DOM & 0.064 & \multirow[t]{2}{*}{0.045} \\
\hline & & REC & 0.031 & \\
\hline
\end{tabular}

\#, Wilcoxon Mann-Whitney $U$ test for the gefitinib trough concentration among different genotype model groups; *, Krustal-Wallis $\mathrm{H}$ test for the gefitinib blood concentration among different genotype groups. DOM, dominant model; REC, recessive model. 

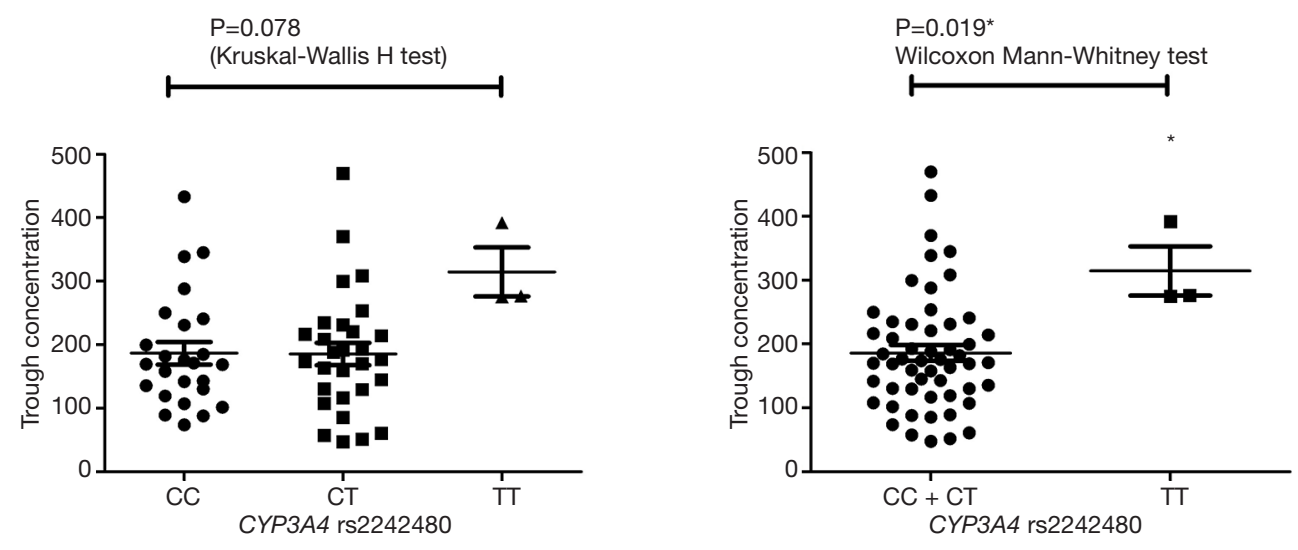

Figure S2 The distribution of gefitinib trough concentration in CYP3A4 rs2242480 genotype groups. *, P value $<0.05$.
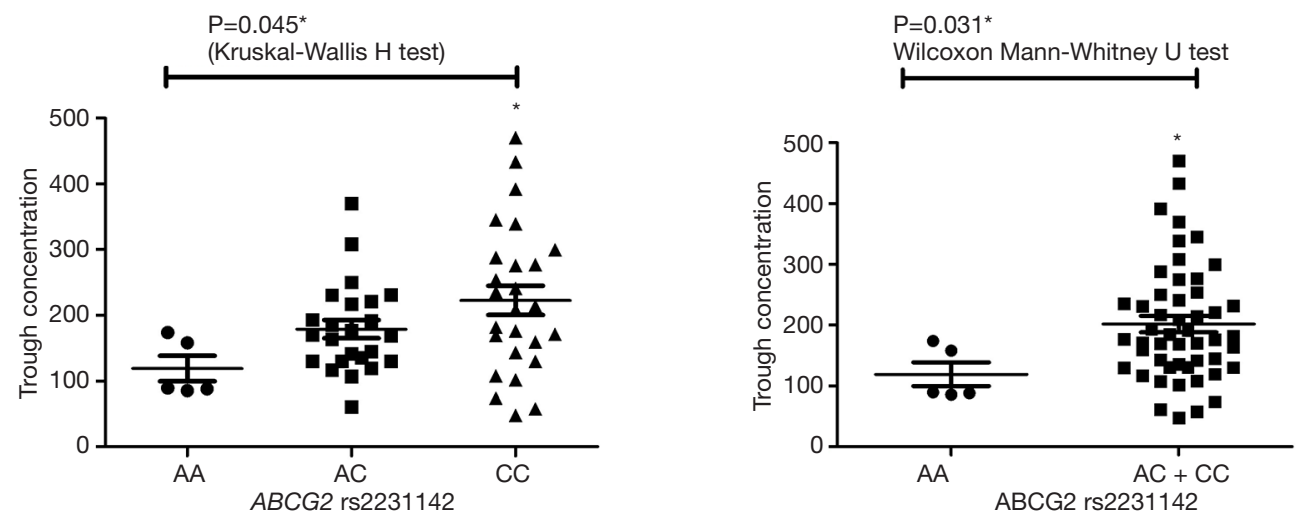

Figure S3 The distribution of gefitinib trough concentration in ABCG2 rs2231142 genotype groups. *, $\mathrm{P}$ value $<0.05$.

Table S4 Log-rank test for PFS between patients with $\mathrm{C}_{\text {trough }}$ $<200 \mathrm{ng} / \mathrm{mL}$ and $\mathrm{C}_{\text {trough }}>200 \mathrm{ng} / \mathrm{mL}$

\begin{tabular}{lcccc}
\hline \multirow{2}{*}{ Group } & \multirow{2}{*}{ Median } & \multirow{2}{*}{$\begin{array}{l}\text { Standard } \\
\text { deviation }\end{array}$} & \multicolumn{2}{l}{ 95\% confidence intervals } \\
\cline { 4 - 5 } & & & Lower & Upper \\
\hline $\mathrm{C}_{\text {trough }}<200 \mathrm{ng} / \mathrm{mL}$ & 14.000 & 2.880 & 8.355 & 19.645 \\
$\mathrm{C}_{\text {trough }}>200 \mathrm{ng} / \mathrm{mL}$ & 11.800 & 4.591 & 2.802 & 20.798 \\
Total & 13.533 & 3.073 & 7.510 & 19.556 \\
\hline
\end{tabular}

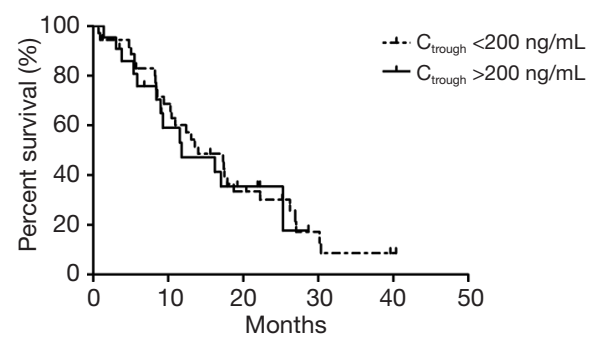

Figure S4 The Kaplan-Meier curve of the PFS in high trough concentration $(>200 \mathrm{ng} / \mathrm{mL})$ group compared with that in low trough concentration $(<200 \mathrm{ng} / \mathrm{mL})$ group. PFS, progression free survival.
Table S5 Multivariable logistic regression analysis of ORR

\begin{tabular}{lccc}
\hline Parameter & $\mathrm{P}$ & OR & $95 \% \mathrm{Cl}$ \\
\hline Intercept & 0.037 & 9.000 & \\
rs2032582 (TT + GT/GG) & 0.047 & 0.111 & 0.013 to 0.965 \\
\hline $\begin{array}{l}\text { OR, odds ratio; 95\% Cl, confidence interval. ORR, overall } \\
\text { response rate. }\end{array}$ & & &
\end{tabular}

Table S6 Multivariable Cox regression of PFS

\begin{tabular}{lccc}
\hline Parameter & Odds ratio & $95 \% \mathrm{Cl}$ of OR & $\mathrm{P}$ \\
\hline Rs2242480DOM & 7.542 & 2.082 to 27.319 & 0.002 \\
Rs10256836REC & 2.170 & 1.136 to 4.146 & 0.019 \\
\hline
\end{tabular}

OR, odds ratio; DOM, dominant model; REC, recessive model. PFS, progression free survival. 